Margarida Araújo Barbosa Miranda ${ }^{1}$ Danielle Rosa Evangelista ${ }^{1}$ Wellington Gomes Miranda ${ }^{2}$

\title{
CONTRACEPÇÃO PERMANENTE POR INSERÇÃO DE DISPOSITIVO INTRATUBÁRIO SOB A PERSPECTIVA DA LEI N. 9.263/1996*
}

Permanent contraception by insertion of intra-tubular device under the perspective of the Brazilian Law no. 9.263/1996

${ }^{1}$ Universidade Federal de Tocantins. Palmas/TO, Brasil.

${ }^{2}$ Ministério Público do Estado do Tocantins. Palmas/TO, Brasil.

Correspondência: Margarida Araújo Barbosa Miranda. E-mail: guidaneta2@gmail.com

Recebido: 02/05/2018. Revisão: 15/10/2018. Aprovado: 31/10/2018.

\footnotetext{
*Artigo elaborado a partir da dissertação de mestrado não publicada intitulada "Conhecimento, satisfação e repercussões clínicas relacionadas à contracepção permanente por inserção de dispositivo intratubário", realizada na Universidade Federal do Tocantins, Palmas, Tocantins, Brasil.
} 


\section{RESUMO}

Este é um estudo transversal, de abordagem quantitativa e caráter descritivo, que objetivou analisar o fluxo de encaminhamento das mulheres ao serviço de referência em esterilização por meio de inserção do dispositivo intratubário contracepção permanente, no contexto da legislação vigente em planejamento reprodutivo. A população foi composta por 32 mulheres, residentes em Palmas (Tocantins) e submetidas à inserção do dispositivo intratubário em serviço público de referência estadual. Os dados foram coletados de junho a outubro de 2017 em entrevista semiestrutura e analisados no programa Stata, versão 14.0. As variáveis categóricas foram descritas por meio de proporção e as contínuas, por média e desvio-padrão. $\mathrm{O}$ perfil sociodemográfico mostrou mulheres com 35,2 $\pm 2,9$ anos de idade, maioria com parceria fixa e parda, ensino médio como nível de escolaridade predominante e ocupando funções variadas. A média do número de filhos foi de $2,8 \pm 1,1$. A média do tempo de espera para a inserção do dispositivo intratubário foi de 2,5 meses. Todas as mulheres inseriram o dispositivo intratubário fora do período gravídico puerperal. A média de idade das mulheres à época do procedimento foi de $31,9 \pm 3$ anos. Os dados revelaram agilidade do serviço no atendimento à mulher, considerando o pouco tempo entre a manifestação da vontade e a realização do procedimento, porém respeitando o limite mínimo exigido pela legislação brasileira. De um modo geral, houve observância dos aspectos legais pelo serviço de referência, com exceção da notificação de esterilização. Constatou-se a necessidade de revisar o paradigma da autorização do cônjuge para a realização do procedimento, ante a violação dos direitos sexuais e reprodutivos.

\section{Palavras-Chave}

Esterilização Tubária; Histeroscopia; Legislação; Planejamento Familiar.

\section{ABSTRACT}

Cross-sectional study of quantitative approach and descriptive character, which aimed to analyze the flow of referral of women to the referenced sterilization service through the insertion of intra-tubular device of permanent contraception, in the context of the current legislation in reproductive planning. The population was composed of 32 women, living in Palmas (Tocantins) and submitted to the insertion of the intra-tubular device at a state public service of reference. The data were collected from June to October 2017, using a semistructured interview and analyzed with the Program Stata, version 14.0. Categorical variables were described by means of proportion and the continuous variables, by mean and standard deviation. The sociodemographic profile showed women with $35.2 \pm 2.9$ years of age, the majority brown women, with steady partners, high school as predominant level of education and performing varied jobs. The mean number of children was $2.8 \pm 1$. The mean waiting time for insertion of the intra-tubular device was 2.5 months. All the women received the intra-tubular device outside the puerperal pregnancy period. The mean age at the time of the procedure was $31.9 \pm 3$ years. The data revealed the swiftness of the service, considering the short time between the request and the performance of the procedure, but respecting the minimum limit required by the Brazilian legislation. In general, the reference service complied with legal aspects, except for the notification of sterilization. It was verified the need to revise the paradigm of the authorization of the spouse to carry out the procedure, in view of the violation of sexual and reproductive rights.

\section{Keywords}

Tubal Sterilization; Hysteroscopy; Legislation; Family Planning. 
As leis não bastam. Os lírios não nascem da lei. ${ }^{1}$

\section{Introdução}

A contracepção permanente por inserção de dispositivo intratubário (DIT), é um procedimento realizado em regime ambulatorial, por histeroscopia, sem necessidade de anestesia. O tempo rápido de procedimento - varia de 8,1 minutos a 13 minutos, com alta da mulher de 30 minutos a 60 minutos após a realização - é uma das vantagens desse método. $\mathrm{O}$ dispositivo expande ao ser liberado e acomoda-se no primeiro terço da tuba uterina, ocasionando uma reação tecidual natural e consequente obstrução da tuba uterina após 90 dias² $^{2}$.

Aprovado em 2002 pela Food and Drug Administration (FDA) - órgão do governo dos Estados Unidos criado em 1862 com a função de controlar os alimentos e medicamentos, por meio de testes e pesquisas -, é comercializado com o nome Essure e consiste em uma microespiral formada de fibras de poliéster (dácron), níquel e titânio ${ }^{3}$.

A Portaria GM n. 2.084/2005 prevê a aquisição direta e distribuição dos anticoncepcionais hormonais pelo Ministério da Saúde aos estados, municípios e Distrito Federal, bem como o financiamento dos produtos contraceptivos (dispositivo intrauterino, diafragma), por meio do Sistema Único de Saúde (SUS). Nessa portaria, não consta o DIT no rol dos insumos disponibilizados ${ }^{4}$.

No Brasil, a esterilização feminina é regulada pela Lei n. $9.263 / 1996^{5}$, que trata do planejamento familiar, sendo garantida no SUS por meio da laqueadura tubária convencional. Todavia, alguns estados disponibilizam e/ou já disponibilizaram, pelo SUS, o DIT de contracepção permanente, como é o caso do Espírito Santo, de São Paulo, do Distrito Federal e do Tocantins.

Apesar de o DIT não ter sido contemplado no elenco de métodos contraceptivos disponibilizados pelo Ministério da Saúde, a Secretaria de Estado da Saúde

\footnotetext{
${ }^{1}$ ANDRADE, Carlos Drummond de. Antologia poética. 1. ed. São Paulo: Companhia das Letras, 2012. (Nosso Tempo).

${ }^{2}$ CONCEPTUS Incorpored. Essure: instructions for use. Mountain View (CA): Conceptus Inc., 2012. Disponível em: http://www.essuremd.com/Portals/essuremd/PDFs/TopDownloads/Essure\%20IFU\%200ct\%205\%20 2011.pdf. Acesso em: 15 dez. 2017.

${ }^{3}$ FEDERAÇÃO BRASILEIRA DAS ASSOCIAÇÕES DE GINECOLOGIA E OBSTETRÍCIA - FEBRASGO. Manual de orientação endoscopia ginecológica. São Paulo: FEBRASGO, 2011. Disponível em: https://www.febrasgo. org.br/images/arquivos/manuais/Manuais_Novos/manualendoscopiaginecologicafinal.pdf.

${ }^{4}$ MINISTÉRIO DA SAÚDE. Portaria n. 2.084, de 26 de outubro de 2005. Estabelece os mecanismos e as responsabilidades para o financiamento da Assistência Farmacêutica na Atenção Básica e dá outras providências. Disponível em: http://www.lex.com.br/doc_547574_PORTARIA_N_2084_DE_26_DE_ OUTUBRO_DE_2005.aspx. Acesso em: 31 mar. 2018.

${ }^{5}$ BRASIL. Lei n. 9.263, de 12 de janeiro de 1996. Regula o $\S 7^{\circ}$ do art. 226 da Constituição Federal, que trata do planejamento familiar, estabelece penalidades e dá outras providências. Disponível em: http://www. planalto.gov.br/ccivil_03/leis/19263.htm. Acesso em: 25 set. 2019.
} 
do Tocantins inaugurou em 2013 um ambulatório para inserção desse dispositivo em mulheres que aguardavam o procedimento de esterilização por laqueadura convencional. O serviço encerrou suas atividades em 2014.

A Agência Nacional de Vigilância Sanitária (Anvisa), por meio da Resolução n. 457/2017 e embasada em relatórios técnico-científicos, classificou o sistema Essure como sendo de risco máximo e o tirou de circulação por um período de cinco meses. O risco foi estabelecido em virtude de complicações como sangramento menstrual, gravidez indesejada, dor crônica, perfuração tubária e migração do dispositivo, alergia e sensibilidade ou reações do tipo imune.

Na ocasião, a Anvisa prestou informações em seu site às mulheres usuárias do dispositivo sobre a necessidade de manterem uma rotina de acompanhamento com o médico, bem como sobre a não recomendação de retirada do dispositivo, salvo em caso de orientação médica nesse sentido. Um formulário foi disponibilizado no FormSus para que essas mulheres pudessem notificar possíveis complicações em virtude do DIT de contracepção permanente ${ }^{7}$.

A Anvisa liberou novamente o produto após a empresa responsável cumprir as exigências impostas, dentre elas a apresentação de relatórios de estudos clínicos que incluíssem, entre outros aspectos, informações críticas referentes à segurança do produto 8 .

A FDA acredita que algumas mulheres não recebam ou compreendam informações sobre os riscos e benefícios do DIT de contracepção permanente. Assim, elaborou um documento com recomendações acerca dessas e outras informações, que devem ser repassadas à mulher antes que se submeta ao procedimento de esterilização por implante de dispositivo tubário?.

No site oficial do sistema Essure, há um comunicado alertando acerca das repercussões clínicas relatadas por algumas mulheres, como perfurações, dor persistente e reações de hipersensibilidade, orientando a remoção cirúrgica do dispositivo caso necessário.

\footnotetext{
${ }^{6}$ AGÊNCIA NACIONAL DE VIGILÂNCIA SANITÁRIA - ANVISA. Resolução n. 457, de 17 de fevereiro de 2017. Disponivel em: http://portal.anvisa.gov.br/documents/33868/3253113/RE+457\%2C+de+17+fev+2017+ +Recolhimento/49a57fa2-0247-47be-9642-b0f37a00947c. Acesso em: 25 set. 2019.

'SISTEMA Essure volta a ser liberado. Contraceptivos. Agência Nacional de Vigilância Sanitária, Notícias, Brasília-DF, 12 jul. 2017. Disponivel em: portal.anvisa.gov.br/noticias/-/asset_publisher/FXrpx9qY7FbU/ content/sistema-essure-volta-a-ser-liberado/219201/pop_up?_101_INSTANCE_FXrpx9qY7FbU_ viewMode=print\&_101_INSTANCE_FXrpx9qY7FbU_languageld=pt_BR. Acesso em: 14 abr. 2018.

${ }^{8} / \mathrm{d}$. Ibid.

${ }^{9}$ FOOD AND DRUG ADMINISTRATION - FDA. Labeling for Permanent Hysteroscopically Placed Tubal Implants Intended for Sterilization. Guidance for industry and food and drug administration staff. Federal Register, v. 81, n. 210, p. 75419-75420, Oct. 2016. Disponivel em: https://www.gpo.gov/fdsys/pkg/FR-2016-10-31/ pdf/2016-26243.pdf. Acesso em: 14 abr. 2018.
} 
AVISO: Alguns pacientes implantados com o Sistema Essure ${ }^{\circledR}$ para controle permanente da natalidade sofreram e/ou relataram eventos adversos, incluindo perfuração do útero e/ou trompas de falópio, identificação de inserções na cavidade abdominal ou pélvica, dor persistente e suspeita de alergia, ou reações de hipersensibilidade. Se o dispositivo precisar ser removido para solucionar esse evento adverso, será necessário um procedimento cirúrgico. Essas informações devem ser compartilhadas com os pacientes que consideram a esterilização com o Sistema Essure ${ }^{\circledR}$ de controle permanente de natalidade durante a discussão dos benefícios e riscos do dispositivo ${ }^{10}$ (Tradução dos editores).

Este comunicado faz parte das exigências da FDA ao fabricante, após ter restringido a venda e distribuição do dispositivo em 2016 por entender que as mulheres não estavam sendo adequadamente informadas acerca sobre os riscos do método. De acordo com o órgão, após o alerta na embalagem do material e a implementação de uma lista de verificação de decisão para as pacientes, observou-se uma queda de $70 \%$ na venda do Essure nos EUA ${ }^{11}$.

Recentemente, após tomar conhecimento de que ainda havia mulheres que não estavam sendo adequadamente informadas sobre os riscos do Essure, a FDA emitiu nova ordem de restrição à venda e distribuição do dispositivo a fim de garantir que todas as mulheres em busca desse método sejam informadas sobre os riscos e, assim, possam tomar decisões de forma esclarecida ${ }^{12}$.

Face ao exposto e considerando que se trata de um método pouco estudado e difundido no Brasil, foi realizado um estudo objetivando analisar o fluxo de encaminhamento das mulheres ao serviço de referência em esterilização por meio de inserção do DIT de contracepção permanente, no contexto da legislação vigente em planejamento reprodutivo, para o qual este artigo se volta.

O tipo de estudo foi transversal, utilizando a abordagem quantitativa e de caráter descritivo. A população foi composta por 32 mulheres, residentes em Palmas (TO) e submetidas à inserção do DIT em serviço público de referência estadual. Os

\footnotetext{
10“WARNING: Some patients implanted with the Essure ${ }^{\circledR}$ System for Permanent Birth Control have experienced and/or reported adverse events, including perforation of the uterus and/or fallopian tubes, identification of inserts in the abdominal or pelvic cavity, persistent pain, and suspected allergic or hypersensitivity reactions. If the device needs to be removed to address such an adverse event, a surgical procedure will be required. This information should be shared with patients considering sterilization with the Essure ${ }^{\circledR}$ System of Permanent Birth Control during discussion of the benefits and risks of the device." ESSURE permanent birth control. Disponível em: https://www.pwslawfirm.com/assets/essure/ BBW_Added.pdf. Acesso em: 25 set. 2019.

${ }^{11}$ FOOD AND DRUG ADMINISTRATION. FDA restricts sale and distribution of Essure to protect women and to require that patients receive risk information. FDA News Release, Apr. 9, 2018. Disponível em: https:// www.fda.gov/newsevents/newsroom/pressannouncements/ucm604098.htm. Acesso em: 17 abr. 2018.

${ }^{12}$ Id. Ibid., p. 13.
} 
dados foram coletados de junho a outubro de 2017, utilizando entrevista semiestruturada e analisados no programa Stata versão 14.0. As variáveis categóricas foram descritas por meio de proporção e as contínuas, por média e desvio-padrão.

Em consonância com os critérios éticos exigidos pela Resolução n. 466/2012 do Conselho Nacional de Saúde (CNS) ${ }^{13}$, o trabalho de campo teve início somente após apreciação e aprovação do projeto pelo Comitê de Ética em Pesquisa da Universidade Federal do Tocantins (UFT), por meio do parecer consubstanciado n. 1.857.489, de 08 de dezembro de 2016.

Vale ressaltar que o serviço de esterilização por DIT no Tocantins funcionou nos anos de 2013 e 2014, tendo realizado nesse período 396 procedimentos no município de Palmas. Para este estudo, foram disponibilizados 111 prontuários, sendo 97 de usuárias que completaram o procedimento e 14 que tiveram o procedimento interrompido por condições diversas. Considerando mudanças de município e mulheres não encontradas, foi estabelecido contato para entrevista com 29 usuárias, que prontamente aceitaram participar do estudo e assinaram o Termo de Consentimento Livre e Esclarecido; algumas dessas mulheres, por sua vez, indicaram o endereço e/ou telefone de outras três mulheres, cujos prontuários não foram fornecidos pelo ambulatório, mas que foram incluídas no estudo, totalizando 32 mulheres participantes da pesquisa.

\section{Aspectos legais do planejamento familiar}

O planejamento familiar é resguardado no artigo 226 , parágrafo $7^{\circ}$, da Constituição Federal de 1988 (CF/88), com fundamento no macroprincípio da dignidade da pessoa humana, bem como no da paternidade responsável. Impõe-se ao Estado propiciar, a partir da decisão do casal, recursos em âmbito educacional e científico, para assim garantir o pleno exercício desse direito, de modo não coercitivo por parte de instituições oficiais ou privadas.

Fundado nos princípios da dignidade da pessoa humana e da paternidade responsável, o planejamento familiar é livre decisão do casal, competindo ao Estado propiciar recursos educacionais e científicos para o exercício desse direito, vedada qualquer forma coercitiva por parte de instituições oficiais ou privadas ${ }^{14}$.

Regulando o supramencionado artigo, foi editada, no dia 12 de janeiro de 1996, a Lei n. 9.263, que trata do planejamento familiar e estabelece penalidades.

\footnotetext{
${ }^{13}$ CONSELHO NACIONAL DE SAÚDE. Resolução 466, de 12 de dezembro de 2012. Aprova as diretrizes e normas regulamentadoras de pesquisas envolvendo seres humanos. Disponível em: http://conselho. saude.gov.br/resolucoes/2012/Reso466.pdf. Acesso em: 25 set. 2019.

${ }^{14}$ Art. 226, $\S 7^{\circ}$. BRASIL. Constituição da República Federativa do Brasil de 1988. Disponível em: http://www. planalto.gov.br/ccivil_03/constituicao/constituicaocompilado.htm. Acesso em: 25 set. 2019.
} 
Segundo essa lei, o direito ao planejamento familiar é universal e constitui um "conjunto de ações de regulação da fecundidade que garanta direito iguais de constituição, limitação ou aumento da prole pela mulher, pelo homem ou pelo casal", sendo vedado o controle demográfico.

Importa ressaltar que o planejamento familiar norteia-se por ações de cunho preventivo e educativo, bem como pela garantia de acesso igualitário à regulação da fecundidade, a partir de informações, meios, métodos e técnicas disponíveis, cientificamente aceitos e que não exponham as pessoas a risco, garantindo também a liberdade de opção (Lei n. 9.263/1996).

Quanto à esterilização voluntária, temática deste estudo, a lei estabelece dois critérios para que homens e mulheres se submetam a esse tipo de contracepção: o primeiro é a capacidade civil, e o segundo critério pode ser cumprido pela idade mínima de 25 anos ou pelo número mínimo de dois filhos vivos. Com o cumprimento dos dois critérios, procede-se à manifestação da vontade, após a qual deve-se aguardar no mínimo 60 dias para a realização do procedimento de esterilização. Durante esse período, será assegurado à pessoa acesso a serviço de planejamento reprodutivo que conte com equipe multidisciplinar para o aconselhamento, com vistas ao desencorajamento da esterilização precoce (Lei n. 9.263/1996).

Outra situação em que é permitida a esterilização voluntária diz respeito a circunstâncias em que uma futura gestação ofereça risco à saúde da mulher ou do futuro concepto, caso que deve ser testemunhado em relatório escrito e assinado por dois médicos (Lei n. 9.263/1996).

A expressa manifestação da vontade exigida pela lei como condição à esterilização deve ser registrada em documento escrito e firmado, após a informação a respeito dos riscos do procedimento, possíveis efeitos colaterais, dificuldades de sua reversão e opções de contracepção reversível existentes (Lei n. 9.263/1996). Desconsidera-se a manifestação da vontade quando restarem comprovadas alterações na capacidade de discernimento por influência de álcool, drogas, estado emocional ou incapacidade mental temporária ou permanente ao tempo da assinatura do documento (Lei n. 9.263/1996).

Além disso, mulheres durante o período de parto ou aborto, caso não seja comprovada a necessidade em virtude de cesarianas sucessivas anteriores, não devem ser submetidas ao procedimento de esterilização (Lei n. 9.263/1996).

O DIT de contracepção permanente tem previsão legal no artigo 10, parágrafo $4^{\circ}$, da Lei n. 9.263/1996, segundo o qual a esterilização cirúrgica como método contraceptivo somente será executada por laqueadura tubária, vasectomia ou de outro método cientificamente aceito, sendo vedada esterilização por histerectomia e ooforectomia.

Segundo a lei, na vigência de sociedade conjugal, a esterilização depende do consentimento expresso de ambos os cônjuges, porém essa previsão tem suscitado 
divergências doutrinárias. Entre os principais argumentos contrários, destaca-se a violação aos direitos sexuais e reprodutivos da pessoa, haja vista que a exigência da outorga uxória ou marital viola a autonomia da vontade daquele que pretende adotar a técnica como forma de controle de sua própria fecundidade.

Outrossim, existe uma lacuna na lei no tocante à divergência entre o casal: quando a esposa ou o marido quer realizar a esterilização voluntária, mas seu(sua) cônjuge ou companheiro(a) manifesta-se contrário(a). Nessa situação, o procedimento não poderia ser realizado. Como resolver? Submeter a controvérsia a uma decisão judicial? Ou respeitar a autonomia da vontade do cônjuge e permitir que este possa decidir sobre os direitos reprodutivos e sexuais, de forma a respeitar o princípio da dignidade da pessoa humana, a sacralidade do corpo humano, por se tratar um direito natural e da personalidade, porquanto indisponível, intransmissível e irrenunciável?

Destarte, considera-se crime a esterilização realizada em desacordo com a lei em voga, com pena que varia de dois a oito anos de reclusão, sendo aumentada em um terço se a esterilização for praticada: (i) durante os períodos de parto ou aborto, salvo o disposto no inciso II, do artigo 10; (ii) com manifestação da vontade do esterilizado expressa durante a ocorrência de alterações na capacidade de discernimento por influência de álcool, drogas, estados emocional alterado ou incapacidade mental temporária ou permanente; (iii) através de histerectomia e ooforectomia; (iv) em pessoa absolutamente incapaz sem autorização judicial; e (v) através de cesárea indicada para fim exclusivo de esterilização.

Ademais, cumpre ressaltar que, segundo a Lei de Execução Penal, a pena fixada acima de quatro anos e inferior a oito anos será cumprida em regime semiaberto, em estabelecimento agrícola, industrial ou similar. Se fixada acima de oito anos, será cumprida em regime fechado, ou seja, em penitenciária.

Nesse diapasão, é importante que os profissionais envolvidos no fomento das ações de planejamento familiar conheçam as disposições da mencionada lei, bem como das normas de funcionamento e dos mecanismos de fiscalização estabelecidos pelas instâncias gestoras do SUS, com o fim de garantir uma prestação eficiente, visando a respeitar a atenção à mulher, ao homem ou ao casal.

\section{Resultados e discussão}

As usuárias do DIT de contracepção permanente tinham idade mínima de 29 e máxima de 42 anos, com média 35,2 $\pm 2,9$ anos de idade no dia da entrevista, na sua maioria pardas $(59,4 \%)$ e casadas em união estável ou consensual $(71,9 \%)$, com renda média de $\mathrm{R} \$ 2.606,46 \pm 2.134,35$, com ensino médio incompleto ou completo $(56,3 \%)$, sendo ocupadas principalmente em funções do lar, de diarista, de empregada doméstica, de auxiliar de serviços gerais e de camareira (31,3\%). 
O perfil socioeconômico e demográfico das entrevistadas assemelha-se ao perfil encontrado em outro estudo realizado com mulheres que buscavam método anticoncepcional definitivo, ou seja, a maioria das mulheres esterilizadas apresentam idade média, no momento da esterilização, de 33 anos, renda aproximada de dois salários mínimos, união estável e ensino fundamental incompleto ${ }^{15}$. Ressalta-se que a variável de idade apresenta-se em observância com a Lei n. 9.263/1996, que estabelece a prática de esterilização cirúrgica apenas em mulheres com idade superior a 25 anos.

Apesar de a renda média das mulheres ter sido $\mathrm{R} \$ 2.606,46 \pm 2.134,35$, com variação de $\mathrm{R} \$ 800,00$ a $\mathrm{R} \$ 10.000,00$, destacamos que a moda foi de $\mathrm{R} \$ 1.874,00$, equivalente a dois salários mínimos à época. Logo, a maioria das mulheres vivia com renda inferior à média das mulheres deste estudo. De acordo com a Pesquisa Nacional Demografia e Saúde da Criança e da Mulher (PNDS) ${ }^{16}$, a renda média domiciliar das mulheres entrevistadas residentes em área urbana da macrorregião Norte foi de R $\$ 1.116,83$ (desvio-padrão 78,68), reforçando os dados encontrados.

Quanto às características reprodutivas das mulheres, no momento da entrevista foi identificada uma média de $3,4 \pm 1,4$ gestações entre as usuárias do método,

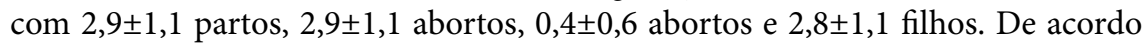
com projeções do Instituto Brasileiro de Geografia e Estatística (IBGE), a Taxa de Fecundidade Total (TFT) no Brasil em 2017 foi de 1,67, enquanto no Tocantins, no mesmo ano, foi de 1,86. Assim, observa-se uma média maior do número de filhos vivos das entrevistadas em relação à média de filhos vivos por mulher ao longo do ciclo reprodutivo (TFT) no Tocantins e no Brasil ${ }^{17}$.

A Tabela 1 apresenta as variáveis referentes aos aspectos legais que envolvem o procedimento de contracepção permanente.

Ao analisar os dados descritos na Tabela 1, acerca dos aspectos legais, verifica-se que a média do tempo de espera, desde a assinatura do Termo de Consentimento Livre e Esclarecido até a inserção do DIT de contracepção permanente, foi de 2,5 meses, com tempo mínimo de espera de dois e máximo de quatro meses, estando em observância ao disposto da legislação brasileira específica, que determina o prazo mínimo de dois meses entre a manifestação da vontade e o ato cirúrgico.

\footnotetext{
${ }^{15}$ SANTOS, Fabiana Januária dos et al. Perfil das mulheres submetidas à laqueadura tubária em um Hospital Universitário, Vitória, Espírito Santo. Revista Brasileira de Pesquisa em Saúde, v. 13, n. 3, p. 22-27, 2011. Disponivel em: http://periodicos.ufes.br/RBPS/article/viewFile/1763/1330. Acesso em: 13 abr. 2018.

${ }^{16}$ MINISTÉRIO DA SAÚDE. Centro Brasileiro de Análise e Planejamento. Pesquisa Nacional de Demografia e Saúde da Criança e da Mulher - PNDS 2006: dimensões do processo reprodutivo e da saúde da criança. Brasília, DF: Ministério da Saúde, 2009. 300 p. (Série G. Estatística e Informação em Saúde). Disponível em: http://bvsms.saude.gov.br/bvs/publicacoes/pnds_crianca_mulher.pdf. Acesso em: 20 fev. 2018.

${ }^{17}$ INSTITUTO BRASILEIRO DE GEOGRAFIA E ESTATÍSTICA - IBGE. Projeções e estimativas da população do Brasil e das Unidades da Federação. 2017. Disponível em: https://www.ibge.gov.br/apps/populacao/ projecao/. Acesso em: 15 abr. 2018.
} 
Tabela 1. Distribuição das mulheres submetidas ao procedimento de inserção do Dispositivo Intratubário (DIT) segundo aspectos legais. Palmas, $2017(n=32)$

\begin{tabular}{|c|c|c|}
\hline Características & $\mathbf{n}$ & $\%$ \\
\hline \multicolumn{3}{|l|}{ Aspectos legais } \\
\hline $\begin{array}{l}\text { Tempo em meses entre a manifestação e a realização do procedimento } \\
\text { (média } \pm \text { desvio-padrão, em meses)* }\end{array}$ & & $2,5 \pm 0,6$ \\
\hline \multicolumn{3}{|l|}{ Assinou o Termo de Consentimento Livre e Esclarecido } \\
\hline Não & 1 & 3,1 \\
\hline Sim & 31 & 96,9 \\
\hline \multicolumn{3}{|l|}{ Cônjuge assinou o Termo de consentimento Livre e esclarecido } \\
\hline Não & 4 & 12,5 \\
\hline Sim & 25 & 78,1 \\
\hline Não se aplica & 2 & 6,3 \\
\hline Ignorado & 1 & 3,1 \\
\hline \multicolumn{3}{|l|}{ Manifestação de vontade } \\
\hline Livre e espontânea & 32 & 100,0 \\
\hline \multicolumn{3}{|l|}{ Período em que realizou o procedimento } \\
\hline Fora do período gravídico puerperal & 32 & 100,0 \\
\hline Idade quando realizou o procedimento (média \pm desvio-padrão, em anos) & & $31,9 \pm 3,0$ \\
\hline Número de filhos na época do procedimento & & $2,9 \pm 1,1$ \\
\hline Total & 32 & 100,0 \\
\hline
\end{tabular}

Nota: *Tempo de espera para inserção do DIT, considerando o tempo em que a usuária deu entrada no processo para realização da laqueadura convencional.

Fonte: Os autores

A assinatura do Termo de Consentimento Livre e Esclarecido constitui-se como critério obrigatório na lei. Esse termo não foi assinado por uma das mulheres $(3,1 \%)$ e por quatro cônjuges $(12,5 \%)$. Nesse sentido, a Portaria do Ministério da Saúde n. 48/1999, no artigo $4^{\circ}$, inciso IV, estabelece:

[...] será obrigatório constar no prontuário médico o registro de expressa manifestação da vontade em documento escrito e firmado, após a informação dos riscos da cirurgia, possíveis efeitos colaterais, dificuldade de reversão e opções de contracepção reversíveis existentes ${ }^{18}$.

De acordo com o artigo 10, parágrafo $1^{\circ}$, da Lei n. 9.263/1996:

É condição para que se realize a esterilização o registro de expressa manifestação da vontade em documento escrito e firmado, após a informação a respeito dos riscos da cirurgia, possíveis efeitos colaterais, dificuldades de sua reversão e opções de contracepção reversíveis existentes.

${ }^{18}$ MINISTÉRIO DA SAÚDE. Secretaria de Assistência à Saúde. Portaria n. 48, de 11 de fevereiro de 1999. Disponível em: http://bvsms.saude.gov.br/bvs/saudelegis/sas/1999/prt0048_11_02_1999.html. Acesso em: 25 set. 2019. 
Infere-se que houve aproveitamento do termo de consentimento do procedimento de laqueadura convencional para o procedimento de inserção do DIT de contracepção permanente, considerando o relato de uma entrevistada que diz não ter assinado o termo de consentimento para o Essure, mas ter assinado o específico para laqueadura três anos antes de ser informada, por meio de contato telefônico do serviço, acerca da disponibilidade do Essure.

Face ao exposto, cumpre ressaltar que, apesar de o DIT de contracepção permanente, assim como a laqueadura, configurar método definitivo, deve-se atentar para suas especificidades em vários aspectos, inclusive a impossibilidade de reversão, sendo possível uma nova gravidez apenas por meio da fertilização in vitro (FIV).

Estes e outros aspectos devem ser ressaltados no processo de decisão da mulher e, portanto, configura-se inadequado o aproveitamento de formulários próprios à laqueadura e à vasectomia, especialmente o termo de consentimento, que deve conter ampla informação sobre características, repercussões clínicas, contraindicações e outras acerca do DIT de contracepção permanente, especialmente por se tratar de método ainda pouco difundido no Brasil.

Ademais, no documento elaborado pela FDA com orientações ao fabricante acerca de informações mínimas a serem repassadas às mulheres, consta anexa a proposta de uma lista de verificação para a decisão sobre se submeter ou não ao procedimento, incluindo as contraindicações ao método (Lei n. 9.263/1996).

Todas as mulheres foram submetidas ao procedimento fora do período gravídico puerperal, aspecto favorável, uma vez que a lei afirma que "é vedada a esterilização cirúrgica em mulher durante os períodos de parto ou aborto, exceto nos casos de comprovada necessidade, por cesarianas sucessivas anteriores" (Lei n. 9.263/1996).

A média de idade das mulheres à época do procedimento foi de 31,9 anos $\pm 3,0$, com mínimo de 25 anos e máximo de 38 - menor que a média de idade de mulheres submetidas à esterilização histeroscópica pelo sistema Essure participantes de um estudo realizado na Espanha por Povedano et al. ${ }^{19}$, que foi de 36 anos, com idade mínima de 19 anos (menor que a deste estudo) e máxima de 49 anos (maior).

Um estudo realizado na França por Legendre et al. ${ }^{20}$, com 306 mulheres submetidas à esterilização histeroscópica por Essure, apontou que a idade média das mulheres foi de 41,4 - portanto, significativamente superior à média de idade das mulheres deste estudo.

\footnotetext{
${ }^{19}$ POVEDANO, B. et al. Complications of hysteroscopic Essure ${ }^{\circledR}$ sterilisation: report on 4306 procedures performed in a single centre. Bjog: An International Journal of Obstetrics \& Gynecology, v. 119, n. 7, p. 795-799, 23 fev. 2012. http://dx.doi.org/10.1111/j.1471-0528.2012.03292.x. Disponível em: https:// obgyn.onlinelibrary.wiley.com/doi/epdf/10.1111/j.1471-0528.2012.03292.x. Acesso em: 05 jan. 2018.

${ }^{20}$ LEGENDRE, Guillaume et al. Regret après stérilisation tubaire hystéroscopique par technique Essure ${ }^{\circledR}$. Journal de Gynécologie Obstétrique et Biologie de la Reproduction, v. 43, n. 5, p. 387-392, May 2014. http://dx.doi.org/10.1016/j.jgyn.2013.10.010.
} 
Percebe-se uma distribuição regular, em diversas faixas etárias, desse método contraceptivo, a depender das legislações e dos aspectos culturais do local.

Ressalta-se, portanto, que a idade das entrevistadas à época do procedimento estava em conformidade com o artigo 10 da Lei n. 9.263/1996, que estabelece a idade mínima de 25 anos ou pelo menos dois filhos vivos como um dos critérios para a esterilização voluntária. $O$ texto do referido artigo traz como condição mínima a capacidade civil plena. Assim, pode-se considerar que as mulheres que foram submetidas ao procedimento atendiam aos critérios estabelecidos pela legislação vigente. Ademais, apesar de os critérios de idade e número de filhos serem estabelecidos como alternativos pela legislação brasileira - ou seja, um ou outro e não necessariamente os dois -, a média de filhos por mulheres à época do procedimento

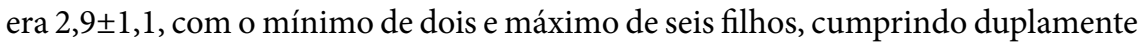
um dos critérios necessários, além da capacidade civil plena.

O número médio de filhos vivos por mulher no dia da entrevista foi $2,8 \pm 1,1$, menor que a média de filhos na ocasião do procedimento $(2,9 \pm 1,1)$, considerando que houve relato de óbito por uma das mulheres.

Observa-se que a motivação para a escolha do método por $100 \%$ das mulheres ocorreu por livre e espontânea vontade, sendo principalmente orientada por profissionais da saúde $(81,3 \%)$. Contudo, uma usuária (E18, 25 anos, quatro filhos) relatou ter sido condicionada pelo cônjuge. Percebe-se, neste caso, uma relação de poder exercida pelo homem sobre o corpo da companheira, violando claramente o direito sexual e reprodutivo da mulher. Outrossim, aponta fragilidade no acompanhamento da usuária pela equipe multiprofissional, uma vez que houve parecer favorável do psicólogo, do médico, do assistente social e do enfermeiro para a realização do procedimento de inserção do DIT de contracepção permanente. A ficha da consulta de enfermagem, anexa ao prontuário da referida mulher, menciona prole grande e situação social desfavorável como justificativas apontadas pela usuária para o procedimento de esterilização. Sobre os direitos reprodutivos, Ventura assevera que:

[...] é o direito subjetivo de toda pessoa decidir sobre o número de filhos e os intervalos entre seus nascimentos, e ter acesso aos meios necessários para o exercício livre de sua autonomia reprodutiva, sem sofrer discriminação, coerção, violência ou restrição de qualquer natureza ${ }^{21}$

Vale ressaltar que a avaliação, pela equipe de saúde, da mulher que está em busca de um método contraceptivo definitivo deve levar em conta condições e critérios de elegibilidade, dentre os quais cita-se a avaliação do relacionamento

${ }^{21}$ VENTURA, Miriam. Direitos reprodutivos no Brasil. 3. ed. Brasília-DF: Fundo de População das Nações Unidas, 2009. 
do casal, o desejo de não querer mais filhos e as pressões emocionais que possam interferir na decisão ${ }^{22}$.

Diante de uma insegurança com relação ao procedimento e do desejo do companheiro, um olhar atento aos termos do que preconiza a Portaria n. 48/1999 do Ministério da Saúde, visando ao aconselhamento e desencorajamento à esterilização precoce, poderia ter identificado essa condição de submissão da mulher que a levou a procurar a contracepção definitiva. Destaca-se que esta foi uma das entrevistadas que referiu arrependimento após o procedimento.

Ainda sobre os aspectos legais, cumpre salientar que não foi encontrada, em nenhum prontuário das mulheres participantes deste estudo, a Ficha de Registro Individual de Notificação de Esterilização, que tem caráter obrigatório conforme estabelece a Portaria n. 48/1999 do Ministério da Saúde.

Com relação à necessidade de consentimento do cônjuge, este tem sido questionado em face dos aspectos que permeiam os direitos sexuais e reprodutivos de homens e mulheres. Nesse sentido, tramita na Câmara dos Deputados o Projeto de Lei n. 7.364/2014 $4^{23}$, com o objetivo de revogar o parágrafo $5^{\circ}$ do artigo $10^{\circ} \mathrm{da}$ Lei n. 9.263/1996 e, assim, excluir a exigência de consentimento do cônjuge. Entre os argumentos do referido PL, cita-se:

$\mathrm{O}$ art. $2^{\circ}$ define o planejamento familiar como "o conjunto de ações de regulação da fecundidade que garante direitos iguais de constituição, limitação ou aumento da prole, pela mulher, pelo homem ou pelo casal". Assim sendo, constata-se que esta lei não considera o planejamento como um privilégio do consenso do casal, mas sim "uma decisão individual de cada ser". Isso se faz certo porque, ainda nesta mesma lei, se encontra um dispositivo - o art. $9^{\circ}$ - em que o legislador teve o cuidado de inserir, para garantir o exercício deste planejamento, que sejam oferecidos todos os métodos contraceptivos cientificamente aceitos, desde que não coloquem em risco a vida e a saúde das pessoas, garantindo a liberdade de opção.

Ressalta-se também que tramitam no Supremo Tribunal Federal (STF) duas ações diretas de inconstitucionalidade: ADI n. $5.097^{24}$, proposta pela Associação

\footnotetext{
${ }^{22}$ MARCOLINO, Clarice. O processo de tomada de decisão na laqueadura tubária. Revista Mineira de Enfermagem, v. 4, n. 1/2, p. 34-40, jan./dez. 2000. Disponível em: http://www.reme.org.br/exportarpdf/827/v4n1a07.pdf. Acesso em: 13 abr. 2018.

${ }^{23}$ BRASIL. Congresso Nacional. Projeto de Lei n. 7.364/2014. Revoga o $\S 5^{\circ}$ do art. $10^{\circ}$ da Lei $n^{\circ} 9.263$, de 12 de janeiro de 1996, que "regula o $\S 7^{\circ}$ do art. 226 da Constituição Federal, que trata do planejamento familiar, estabelece penalidade e dá outras providências". Disponível em: https://www.camara.leg.br/ proposicoesWeb/fichadetramitacao?idProposicao=611328. Acesso em: 25 set. 2019.

${ }^{24}$ SUPREMO TRIBUNAL FEDERAL - STF. ADI n. 5097. Relator: Min. Celso de Melo. Disponível em: http:// portal.stf.jus.br/processos/detalhe.asp?incidente=4542708. Acesso em: 25 set. 2019 .
} 
Nacional dos Defensores Públicos (Anadep), e ADI n. 5.911 $1^{25}$, proposta pelo Partido Socialista Brasileiro (PSB), questionando conformação da Lei n. 9263/1996 com a CF/88.

Na ADI n. 5.097, a Procuradoria Geral da República (PGR) manifestou-se favorável à declaração de inconstitucionalidade do artigo 10 , parágrafo $5^{\circ}$, da Lei n. 9.263/1996, que regulamenta o artigo 226, parágrafo 7 , da $\mathrm{CF} / 88$, que versa sobre a isonomia nos direitos e deveres da sociedade conjugal atribuída igualmente ao homem e à mulher, por entender que a exigência de consentimento de cônjuge ou companheiro(a) como condição para esterilização voluntária de pessoa maior e capaz afronta o princípio basilar da dignidade da pessoa humana: o direito à liberdade e à autonomia da vontade privada.

Ademais, a PGR ressalta que a esterilização voluntária por decisão individual não é incompatível com planejamento familiar, notadamente quando o direito à dignidade da pessoa fundamenta o respeito a seus direitos reprodutivos, a proteção à família e o planejamento familiar (artigo 226, parágrafo $7^{\circ}, \mathrm{CF} / 88$ ). Da mesma forma, não cabe ao Estado, sob pena de macular seu centro de identidade, impor restrições à autodeterminação pessoal em seu aspecto mais natural, que é tratar do direito de ter liberdade, o que, segundo Siches, viola a lógica do razoável ${ }^{26}$.

Nesse mesmo sentido é pensamento de Honneth, para quem o Direito como padrão de reconhecimento é condição fundamental para a constituição do autorrespeito, porque merecedor do respeito de todos os outros ${ }^{27}$. Portanto, a $\mathrm{CF} / 88$, ao impor observância ao núcleo intangível dos direitos fundamentais, atribui ao Estado o dever de promover mecanismos que possibilitem êxitos das escolhas do casal, tanto no sentido da reprodução quanto no da esterilização, sem, contudo, impor restrição à autonomia da vontade.

A ADI n. 5.911, proposta em 2019 pelo PSB, pugna tanto pelo reconhecimento da inconstitucionalidade da exigência do consentimento do cônjuge para a realização da esterilização voluntária, como pela exigência da idade mínima de 25 anos ou ter dois filhos vivos, sob o argumento de que tal exigência vai de encontro com a idade de 18 anos - prevista no Código Civil para atingir a maioridade civil plena -, bem como acaba impondo um dever de procriação, o que por certo viola o princípio da liberdade do casal quanto ao direito ao planejamento familiar e reprodutivo.

Ademais, exigir o consentimento do cônjuge pode ser uma barreira intransponível no acesso das mulheres à contracepção permanente. Nesse sentido, vale ressaltar a fala de algumas das entrevistadas:

\footnotetext{
${ }^{25}$ SUPREMO TRIBUNAL FEDERAL - STF ADI n. 5911. Relator: Min. Celso de Melo. Disponível em: http:// portal.stf.jus.br/processos/detalhe.asp?incidente=5368307. Acesso em: 25 set. 2019.

${ }^{26}$ RECASÉNS SICHES, Luis. Experiência jurídica, naturaleza de la casa e lógica razonable. Unam, México: Fondo de Cultura Económica, 1971.

${ }^{27}$ HONNETH, Axel. Luta por reconhecimento. São Paulo: Editora 34, 2009.
} 
O pai da minha filha assinou porque falaram que era obrigatório. Algumas mulheres não fizeram no dia porque o parceiro não foi. (E09, 31 anos, cinco filhos);

Ele não queria que eu fizesse, por isso não assinou. Falei com os profissionais e eles liberaram. (E16, 35 anos, dois filhos);

Tive que falar que não tinha esposo, pois ele não queria assinar. Se dependesse dele, eu não ligaria [as trompas] nunca. Não me arrependo disso, pois as vezes ficava sem tomar remédio porque ele não queria comprar. (E21, 30 anos, três filhos);

Tava (sic) em processo de divórcio, mas mesmo assim ele teve que assinar. (E26, 31 anos, quatro filhos).

De acordo com Caetano,

Estudos realizados nos anos que se seguiram à regulamentação da lei do planejamento familiar indicam que esta, de forma não antecipada, engendrou obstáculos ao acesso à laqueadura tubária no âmbito do Sistema Único de Saúde (SUS). Tais obstáculos estariam relacionados com a adoção, por parte dos serviços e médicos, de critérios de idade e número de filhos mais restritivos do que os presentes na portaria regulatória, necessidade de obter a anuência por escrito do cônjuge, demora entre a solicitação e a realização do procedimento, proibição da laqueadura no parto e pós-parto, além de uma cobertura territorial limitada de serviços médicos do SUS credenciados para ofertar a esterilização cirúrgica feminina ${ }^{28}$.

Assim, conclui-se que a imposição legal do consentimento de ambos os cônjuges fere a autodeterminação da pessoa sobre o próprio corpo, no âmbito das liberdades e dos direitos individuais reconhecidos nos pactos e convenções de direitos humanos e na $\mathrm{CF} / 88$. Especialmente, considerando a histórica desigualdade de gênero em desfavor da mulher, cria maiores obstáculos para o acesso à esterilização, expondo-a ao risco de gravidez indesejada em meio ao cenário de criminalização do aborto. ${ }^{29}$

Os dados revelaram agilidade do serviço no atendimento à mulher, considerando o pouco tempo entre a manifestação da vontade e a realização do procedimento, porém respeitando o limite mínimo exigido pela legislação brasileira. De um modo geral, o serviço de referência observou os aspectos legais, como a assinatura do termo de consentimento livre e esclarecido pela quase totalidade das mulheres

\footnotetext{
${ }^{28}$ CAETANO, André Junqueira. Esterilização cirúrgica feminina no Brasil, 2000 a 2006: aderência à lei de planejamento familiar e demanda frustrada. Revista Brasileira de Estudos de População, v. 31, n. 2, p. 309-331, dez. 2014. http://dx.doi.org/10.1590/s0102-30982014000200005. Disponível em: http:// www.scielo.br/pdf/rbepop/v31n2/a05v31n2.pdf. Acesso em: 15 jan. 2018.. 2014. Disponível em: <http:// dx.doi.org/10.1590/s0102-30982014000200005>. Acesso em: 15 jan. 2018.

${ }^{29} / d$. Ibid., p. 33
} 
e pela grande maioria dos cônjuges, o cumprimento dos critérios de no mínimo dois filhos vivos ou idade mínima de 25 anos por todas as mulheres, bem como a realização do procedimento fora do período gravídico puerperal.

Contudo, supõe-se que não fora realizada notificação de esterilização de nenhuma das usuárias, considerando que a ficha específica para este fim não foi localizada nos prontuários das participantes deste estudo, conforme estabelece o Ministério da Saúde, sendo a notificação de caráter obrigatório na legislação.

Sobre o termo de consentimento, ficou evidente neste estudo o constrangimento vivenciado por algumas mulheres em face da necessidade de autorização do cônjuge, o que ratifica a premente necessidade de rever a legislação com vistas a desobrigar não apenas mulheres, mas também os homens dessa condição vexatória para o exercício do direito reprodutivo, considerando notória lesão ao princípio da autonomia da vontade e da dignidade da pessoa humana - especialmente em relação às mulheres, devido à desigualdade de gênero que limita o poder de negociação com o companheiro, dificultando por vezes o acesso ao método contraceptivo ou mesmo responsabilizando-as unilateralmente pelo controle da fertilidade, conforme percebido nas falas de algumas entrevistadas neste estudo.

Infere-se, a partir da fala de entrevista, o aproveitamento de formulários próprios dos métodos cirúrgicos (laqueadura e vasectomia) no fluxo de atenção às usuárias do DIT de contracepção permanente, porém sem alteração de seu conteúdo, o que, provavelmente. Isso pode ter gerado inconsistências e fragilidades no processo de aconselhamento, considerando as especificidades desse método em vários aspectos, inclusive a impossibilidade de reversão, sendo possível uma nova gravidez apenas por meio da fertilização in vitro (FIV).

Por fim, vale ressaltar que, considerando o caráter dinâmico do SUS, é desejável a incorporação de novas tecnologias que surjam com o propósito de melhorar a qualidade de vida de seus usuários. Contudo, essa inclusão deve ser ancorada, minimamente, em evidências científicas amplamente discutidas e solidificadas, devendo-se levar em conta aspectos éticos e legais, bem como a repercussão da tecnologia pretendida no contexto biológico, psicológico, social e econômico, além do cenário de possibilidades de efetivação de políticas públicas, incluindo a perspectiva de sustentabilidade, a fim de evitar frustração de expectativas dos indivíduos e vazios assistenciais.

\section{Considerações finais}

A busca no banco de dados na Biblioteca Virtual de Saúde (BVS) revelou a existência de poucos estudos realizados no mundo sobre o DIT de contracepção permanente - alguns deles com declaração de conflito de interesses expressa, outros implícita - e um número ínfimo desses estudos no Brasil, mesmo após a Anvisa tirar provisoriamente o Essure de circulação em 2017. Assim, faz-se necessário aumentar o escopo de estudos sobre o método no Brasil, ampliando o processo de investigação acerca das mulheres 
que foram submetidas ao procedimento de inserção do DIT pelo SUS e incluindo outros aspectos, tais como o contexto de implantação dos serviços, a sustentabilidade, o envolvimento da Atenção Primária, o olhar dos profissionais acerca do método, dentre outros. Um estudo multicêntrico envolvendo todos os estados em que houve implantação de DIT seria importante para elucidar estes e outros aspectos acerca dessa experiência no SUS.

\section{Referências}

ANDRADE, Carlos Drummond de. Antologia poética. 1. ed. São Paulo: Companhia das Letras, 2012. (Nosso Tempo).

CAETANO, André Junqueira. Esterilização cirúrgica feminina no Brasil, 2000 a 2006: aderência à lei de planejamento familiar e demanda frustrada. Revista Brasileira de Estudos de População, v. 31, n. 2, p. 309-331, dez. 2014. http://dx.doi.org/10.1590/s0102-30982014000200005. Disponível em: http://www.scielo.br/pdf/rbepop/v31n2/a05v31n2.pdf. Acesso em: 15 jan. 2018.

CONCEPTUS Incorpored. Essure: instructions for use. Mountain View (CA): Conceptus Inc., 2012. Disponível em: http://www.essuremd.com/Portals/essuremd/PDFs/TopDownloads/ Essure\%20IFU\%20Oct\%205\%202011.pdf. Acesso em: 15 dez. 2017.

ESSURE permanent birth control. Disponível em: https://www.pwslawfirm.com/assets/essure/ BBW_Added.pdf. Acesso em: 25 set. 2019.

FEDERAÇÃO BRASILEIRA DAS ASSOCIAÇÕES DE GINECOLOGIA E OBSTETRÍCIA - FEBRASGO. Manual de orientação endoscopia ginecológica. São Paulo: FEBRASGO, 2011. Disponível em: https:/www.febrasgo.org.br/images/arquivos/manuais/Manuais_Novos/ manualendoscopiaginecologicafinal.pdf.

FOOD AND DRUG ADMINISTRATION - FDA. Labeling for Permanent Hysteroscopically Placed Tubal Implants Intended for Sterilization. Guidance for industry and food and drug administration staff. Federal Register, v. 81, n. 210, p. 75419-75420, Oct. 2016. Disponível em: https://www.gpo.gov/fdsys/pkg/FR-2016-10-31/pdf/2016-26243.pdf. Acesso em: 14 abr. 2018.

FOOD AND DRUG ADMINISTRATION - FDA. FDA restricts sale and distribution of Essure to protect women and to require that patients receive risk information. FDA News Release, Apr. 9, 2018. Disponível em: https://www.fda.gov/newsevents/newsroom/pressannouncements/ ucm604098.htm. Acesso em: 17 abr. 2018.

HONNETH, Axel. Luta por reconhecimento. São Paulo: Editora 34, 2009.

INSTITUTO BRASILEIRO DE GEOGRAFIA E ESTATÍSTICA - IBGE. Projeções e estimativas da população do Brasil e das Unidades da Federação. 2017. Disponível em: https://www.ibge. gov.br/apps/populacao/projecao/. Acesso em: 15 abr. 2018.

LEGENDRE, Guillaume et al. Regret après stérilisation tubaire hystéroscopique par technique Essure $^{\circledR}$. Journal de Gynécologie Obstétrique et Biologie de la Reproduction, v. 43, n. 5, p. $387-$ 392, May 2014. http://dx.doi.org/10.1016/j.jgyn.2013.10.010. 
MARCOLINO, Clarice. O processo de tomada de decisão na laqueadura tubária. Revista Mineira de Enfermagem, v. 4, n. 1/2, p. 34-40, jan./dez. 2000. Disponível em: http://www. reme.org.br/exportar-pdf/827/v4n1a07.pdf. Acesso em: 13 abr. 2018.

MINISTÉRIO DA SAÚDE. Centro Brasileiro de Análise e Planejamento. Pesquisa Nacional de Demografia e Saúde da Criança e da Mulher - PNDS 2006: dimensões do processo reprodutivo e da saúde da criança. Brasília, DF: Ministério da Saúde, 2009. 300 p. (Série G. Estatística e Informação em Saúde). Disponível em: http://bvsms.saude.gov.br/bvs/publicacoes/pnds_ crianca_mulher.pdf. Acesso em: 20 fev. 2018.

POVEDANO, B. et al. Complications of hysteroscopic Essure ${ }^{\circledR}$ sterilisation: report on 4306 procedures performed in a single centre. Bjog: An International Journal of Obstetrics \& Gynecology, v. 119, n. 7, p. 795-799, 23 fev. 2012. http://dx.doi.org/10.1111/j.14710528.2012.03292.x. Disponível em: https://obgyn.onlinelibrary.wiley.com/doi/epdf/10.1111/ j.1471-0528.2012.03292.x. Acesso em: 05 jan. 2018.

RECASÉNS SICHES, Luis. Experiência jurídica, naturaleza de la casa e lógica razonable. Unam, México: Fondo de Cultura Económica, 1971.

SANTOS, Fabiana Januária dos et al. Perfil das mulheres submetidas à laqueadura tubária em um Hospital Universitário, Vitória, Espírito Santo. Revista Brasileira de Pesquisa em Saúde, v. 13, n. 3, p. 22-27, 2011. Disponível em: http://periodicos.ufes.br/RBPS/article/ viewFile/1763/1330. Acesso em: 13 abr. 2018.

SISTEMA Essure volta a ser liberado. Contraceptivos. Agência Nacional de Vigilância Sanitária, Notícias, Brasília-DF, 12 jul. 2017. Disponível em: portal.anvisa.gov.br/noticias/-/ asset_publisher/FXrpx9qY7FbU/content/sistema-essure-volta-a-ser-liberado/219201/ pop_up?_101_INSTANCE_FXrpx9qY7FbU_viewMode=print\&_101_INSTANCE_ FXrpx9qY7FbU_languageId=pt_BR. Acesso em: 14 abr. 2018.

VENTURA, Miriam. Direitos reprodutivos no Brasil. 3. ed. Brasília-DF: Fundo de População das Nações Unidas, 2009.

Margarida Araújo Barbosa Miranda - Mestrado em Ciências da Saúde pela Universidade Federal do Tocantins (UFT); graduanda do Curso de Direito da Faculdade Católica do Tocantins. Enfermeira. Palmas/TO, Brasil.E-mail: guidaneta2@gmail.com

Danielle Rosa Evangelista - Doutorado em Enfermagem pela Universidade Federal do Ceará (UFC). Professora da Universidade Federal do Tocantins (UFT) na disciplina Saúde Sexual e Ciclo Reprodutivo da Mulher. Palmas/TO, Brasil.E-mail: daniellerosa@mail.uft.edu.br

Wellington Gomes Miranda - Mestrado em Prestação Jurisdicional e Direitos Humanos pela Escola Superior da Magistratura Tocantinense (ESMAT/UFT). Professor do Curso de Direito da Faculdade Católica do Tocantins. Analista Ministerial em Ciências Jurídicas do Ministério Público Estadual do Tocantins. Palmas/TO, Brasil.E-mail: wellington900@hotmail.com 